Pengukuran Resistivitas Model ...

\title{
PENGUKURAN RESISTIVITAS MODEL TEROWONGAN DALAM RANGKA EVALUASI DESAIN SISTEM MONITORING MENGGUNAKAN METODA RESISTIVITAS
}

\author{
Firman Syaifuddin \\ Jurusan Teknik Geofisika, FTSP, Institut Teknologi Sepuluh Nopember \\ e-mail: firman@geofisika.its.ac.id
}

\begin{abstract}
Abstrak. Perkembangan teknologi transportasi masal yang berkembang di indonesia khususnya di daerah perkotaan saat ini banyak terkendala oleh kurang tersedianya lahan, sehingga memaksa pemerintah untuk membuat sarana transportasi masal dengan kebutuhan lahan minim, salah satu alternatif solusi adalah sarana transportasi dengan sistem terowongan. Kondisi iklim Indonesia yang memiliki tingkat kelembaban udara dan tingkat pelapukan yang tinggi mengakibatkan mudah berkurangnya kekuatan suatu bangunan khususnya terowongan yang dibangun di bawah permukaan tanah. Hal ini sangat dipengaruhi oleh tingkat kejenuhan air pada lapisan tanah atau batuan penutup suatu terowongan. Dengan memanfaatkan sifat resistivitas air yang rendah maka dapat dilakukan monitoring kekuatan suatu bangunan terowongan dengan metoda resisitivitas. Metoda resistivitas adalah salah satu metoda geofisika yang memanfaatkan sifat kelistrikan suatu meterial tertentu untuk mengetahui kondisi suatu lapisan tanah atau batuan di bawah permukaan. Pada penelitian ini, sebagai bagian dari evaluasi desain sistem monitoring kondisi bangunan terowongan dilakukan pembuatan model fisik terowongan dengan skala tertentu. Model fisik dibuat dengan menggunakan beberapa material yang berbeda agar dapat merepresentasikan sifat batuan pada kondisi sebenarnya. Hasil pengukuran resistivitas secara jelas dapat menunjukan adanya terowongan yang memiliki nilai resistivitas tinggi sedangkan lapisan yang tingkat kejenuhan airnya tinggi ditunjukan dengan nilai resistivitas yang rendah.
\end{abstract}

Kata Kunci: terowongan; metoda resistivitas; monitoring

\begin{abstract}
The development of mass transportation technology developed in Indonesia, especially in urban areas today many are constrained by the lack of availability of land, forcing the government to make mass transportation with minimal land requirements, an alternative solution is a means of transportation to the tunnel system. Indonesia climatic conditions which have high levels of air humidity and high levels of lead easily weathering the reduction in strength of a building, especially a tunnel built below ground level. It is highly influenced by the level of water saturation in the layers of soil or rock cover of a tunnel. By utilizing the resistivity properties of low water, it can be done monitoring the strength of building tunnels with resistivity method. Resistivity method is one of the geophysical methods that utilize the electrical properties of a particular materiality to determine the condition of a layer of soil or rock below the surface. In this study, as part of the evaluation of the design of tunnel building condition monitoring system conducted by making physical models of the tunnel with a certain scale. Physical models are created using several different materials in order to represent the nature of the rocks on the actual conditions. The results of resistivity measurements can clearly show the existence of the tunnel has a high resistivity value while lining the high water saturation level indicated by low resistivity values.
\end{abstract}

Keywords: tunnel; resistivity method; monitoring

\section{PENDAHULUAN}

Seiring berkembangnya suatu wilayah perkotaan karena pertumbuhan ekonomi terjadi pula peningkatan kebutuhan lahan sebagai dampak langsung dari pertumbuhan ekonomi tersebut. Kebutuhan lahan menjadi permasalahan besar ketika jumlah lahan yang tetap tetapi jumlah penduduk yang semakin meningkat. Kebutuhan lahan pada suatu wilayah perkotaan antara lain kebutuhan akan lahan hunian, kebutuhan lahan untuk area perkantoran serta kebutuhan lahan untuk sarana prasarana umum baik sebagai pendukung langsung perekonomian yangberjalan pada suatu wilayah maupun sarana umum yang berhubungan dengan kehidupan sosial kemasyarakatan penduduk perkotaan. Sistem transportasi pada wilayah perkotaan dapat diibaratkan sebagai aliran darah dari kegiatan 
perekonomian yang terjadi pada suatu wilayah, sehingga untuk mendukung agar kegiatan perekonomian dapat berjalan lancar diperlukan sebuah sistem transportasi yang baik. Kondisi transportasi wilayah perkotaan di Indonesia saat ini seolah-olah sering menjadi penghambat roda ekonomi yang berjalan, sehingga diperlukan terobosan dalam pengembangan sistem trasnportasi yang baik. Akhir-akhir ini khususnya di Jakarta yang merupakan urat nadi ekonomi Indonesia telah dikembangkan sebuah sistem transportasi masal yang diharapkan mampu menjadi solusi permasalahan kepadatan jalan dan keterbatasan lahan untuk pembangunan sarana umum khususnya jalan. Sistem transportasi tersebut adalah sistem transportasi yang menggunakan jalur bawah tanah atau terowongan sebagai jalur lintasan moda transportasi masal.

Terowongan sebagai jalur transportasi merupakan alternatif solusi dari permasalahan ketersedian lahan di permukaan yang akan digunakan sebagai sarana transportasi penduduk (balitbang.pu.go.id). Terowongan adalah sebuah terusan atau tembusan yang berada di bawah permukaan tanah yang menghubungkan antar lokasi tertentu. Pemanfaatan teknologi terowongan saat ini telah berkembang pesat, diantaranya pemanfaatan terowongan pada industri pertambangan yang digunakan sebagai jalur eksploitasi material tambang dibawah permukaan tanah pada pertambangan tertutup. Selain pada industri pertambangan. Teknologi terowongan juga dimanfaatkan pada berbagai bidang lain seperti jalur transportasi, pembangkit listrik tenaga air, penyimpanan cadangan gas, dan lain sebagainya.

Sebuah sistem yang baik dengan memanfaatkan teknologi diwajibkan memiliki tingkat keamanan yang tinggi. Pada sistem terowongan yang dimanfaatkan sebagai jalur transportasi harus mampu menjamin keselamatan pengguna jalur tersebut, sehingga dalam pemanfaatan teknologi atau sistem terowongan perlu dilakukan pemantauan kondisi terowongan secara berkala untuk menghindari terjadinya kegagalan dari sistem terowongan yang telah direncanakan. Pemantauan atau sistem monitoring terowongan perlu dirancang sebelum terowongan tersebut dibangun agar dapat diaplikasikan ketika terowongan tersebut dimanfaatkan.

Kondisi iklim Indonesia yang memiliki tingkat kelembaban tinggi dapat mengakibatkan perubahan sifat fisik batuan atau tanah yang berada di lingkungan sebuah terowongan di Indonesia. Kelembaban secara umum berkaitan langsung dengan tingkat atau kadar air pada batuan atau tanah. Kadar air atau saturasi air yang tinggi pada batuan atau tanah dapat mengakibatkan penambahan beban yang harus ditopang sebuah terowongan. Selain penambahan beban tingkat saturasi air yang tinggi juga dapat mengakibatkan terjadinya pengurangan kekuatan pada dinding beton penyangga sebuah terowongan akibat adanya rembesan air yang terjadi sehingga air mengalami kontak langsung dengan beton penyangga.

Salah satu metoda geofisika yang biasa digunakan dalam penyelidikan air adalah metoda resistivitas, metoda ini memanfaatkan sifat kelistrikan suatu material untuk mengetahui karakteristik dari suatu material. Pada pemanfaatan metoda resistivitas untuk mengetahui kadar air atau kelembaban batuan, keberadaan air pada batuan mempengaruhi besaran parameter resistivitas suatu batuan, sehingga metoda resistivitas ini dapat dengan baik digunakan dalam identifikasi keberadaan air atau mengetahui tingkat kelembaban pada batuan. Biasanya pemanfaatan metoda resistivitas digunakan pada fasa studi geologi dan geofisika sebelum dibangun terowongan.

Sistem monitoring yang banyak dilakukan pada sebuah terowongan biasanya hanya memantau terjadinya perubahan posisi atau displacement yang terjadi pada dinding terowongan. Pada kasus di Indonesia dimana tingkat kelembaban yang tinggi dan curah hujan yang tinggi pula perlu kiranya dilakukan sistem monitoring tingkat kelembaban atau kadar air batuan atau tanah penutup terowongan sehingga dapat memberikan informasi kondisi batuan atau tanah penutup terowongan secara berkala. 
Dalam suatu kegiatan pemantauan atau monitoring perlu dilakukan pengujian dari sistem monitoring yang direncanakan, sehingga nantinya desain sistem monitoring yang diusulkan dapat berjalan sesuai dengan rencana dan fungsinya untuk mencegah kemungkinan kegagalan dari sebuah sistem terowongan. Pada penelitian ini sistem monitoring yang diusulkan adalah menggunakan metoda resistivitas yang mamanfaatkan sifat kelistrikan batuan atau tanah penutup terowongan. Untuk mengoptimalkan pemanfaatan metoda resistivitas sebagai sebuah sistem monitoring akan dilakukan pembuatan desain pengukuran metoda resistivitas dan teknik pengolahan datanya. Pengujian desain sistem monitoring dilakukan dengan membuat model fisik sebuah terowongan dengan skala 1 banding 500 .

\section{METODOLOGI}

Pada paper ini ditunjukan bagaimana memanfaatkan metoda resistivitas sebagai sistem monitoring sebuah terowongan. Hal ini berkaitan dengan desain metoda pengukurannya serta teknik pengolahan datanya.

Dilakukan pembuatan model fisik yang dapat merepresentasikan sebuah terowongan dengan skala tertentu, sehingga pengembangan metoda pengukuran resistivitas dapat diaplikasikan pada model fisik yang telah dibuat.

Pengukuran metoda resistivitas yang dilakukan menggunakan peralatan single channel, sehingga teknik pengolahan yang mungkin digunakan hanya pendekatan 2 dimensi. Pengujian sistem monitoring dengan metoda resistivitas dilakukan pada model fisik dengan dua kondisi, yaitu pada saat kondisi kering dan kondisi jenuh air sebagai ilustrasi kondisi nyata di alam.

Pada penelitian ini dilakukan beberapa tahapan antara lain :

1. Tahap persiapan dan perencanaan

2. Tahap pembuatan model fisik

3. Tahap pengembangan metoda pengukuran dan teknik pengolahan data

4. Tahap uji pengukuran dan analisa.

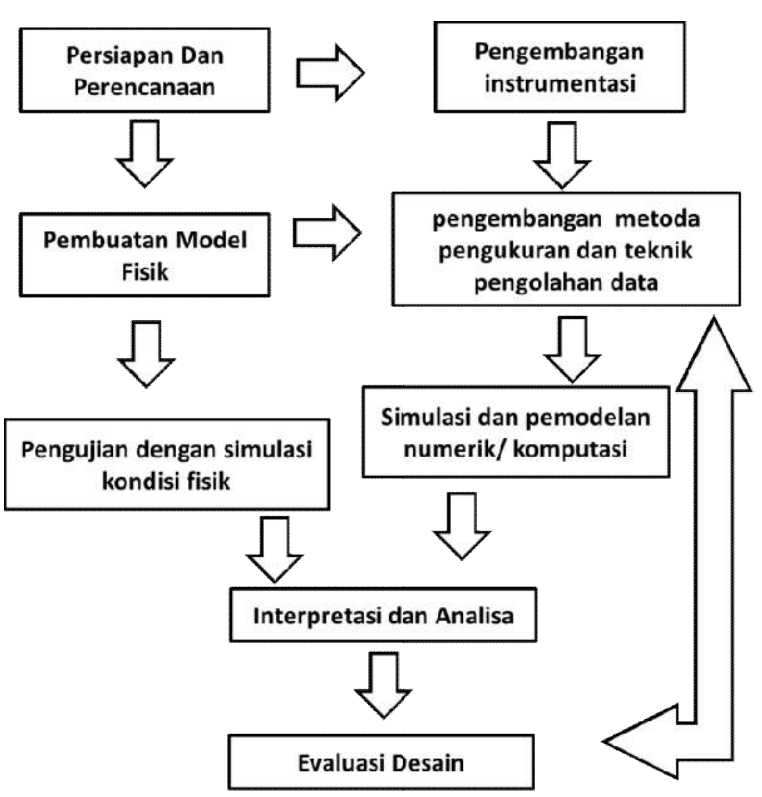

Gambar 1. Diagram Alir Penelitian.

Pengukuran geolistrik dilakukan pada 3 media yang berbeda, yaitu :

\section{a) Media dengan batuan penyusun model}

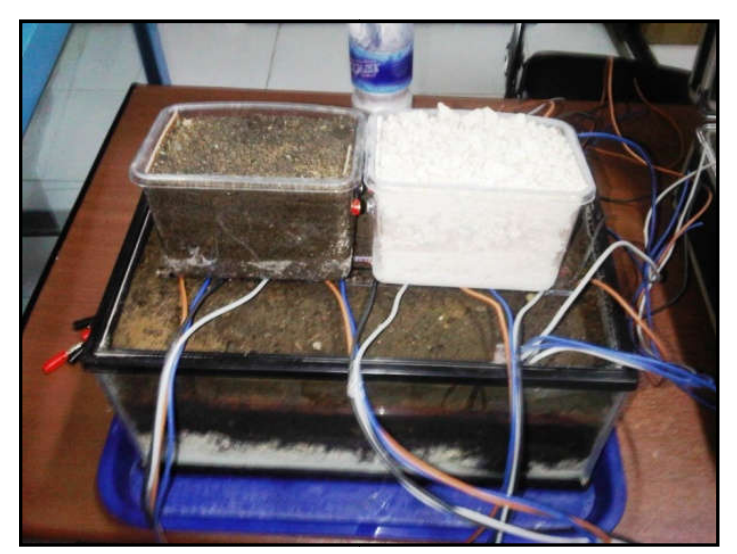

Gambar 2. Batu Gamping dan Batu Pasir.

\section{b) Model fisik dengan dimensi kecil}

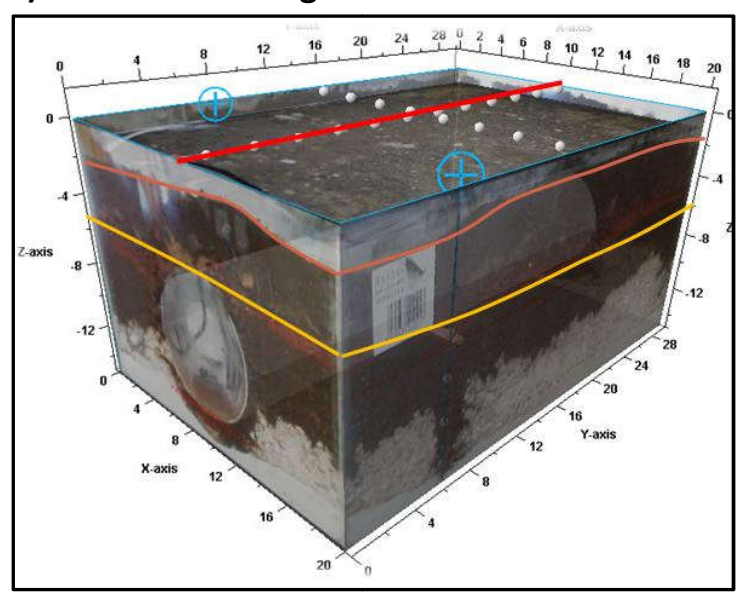

Gambar 3. Model $30 \times 20 \times 15 \mathrm{~cm}$. 


\section{c) Model fisik dengan dimensi 1:500}

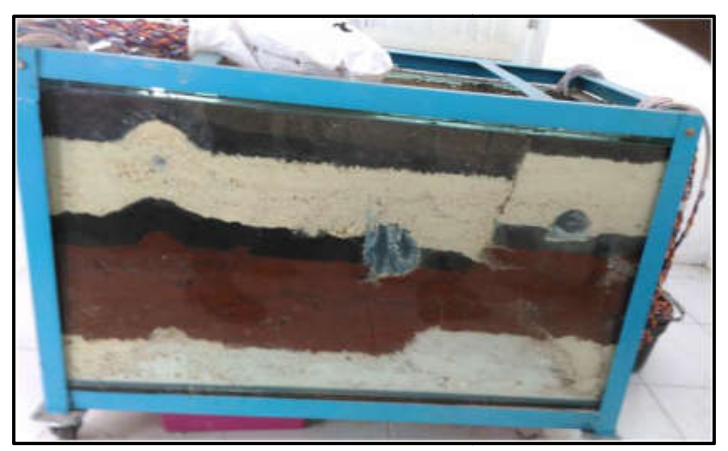

Gambar 4. Model $120 \times 60 \times 60 \mathrm{~cm}$.

\section{HASIL DAN PEMBAHASAN}

Pengukuran resistivitas yang telah dilakukan pada material batuan pengisi model fisik menunjukan perubahan nilai resistivitas yang diakibatkan oleh adanya perubahan nilai saturasi air pada batuan. Pengukuran hanya dilakukan pada bahan batu pasir dan batu gamping dimana kedua batuan tersebut mewakili kelompok batuan dengan nilai resistivitas relatif rendah yaitu batuan pasir dan batuan yang memiliki nilai resistivitas tinggi yaitu batu gamping.

Dari hasil pengukuran nilai resistivitas ditunjukan perubahan nilai yang semakin besar ketika material pada kondisi kering, hal ini dipengaruhi oleh tingkat kejenuhan air, dimana saat mengandung air, nilai resistivitas batuan relatif memiliki nilai yang lebih rendah. Perubahan nilai resistivitas pada batu pasir sebesar 29 persen lebih besar pada kondisi kering dibandingkan nilai resistivitas batu pasir pada kondisi semi basah, sedangkan pada batu gamping perubahan nilai resistivitasnya yaitu 45 persen lebih besar nilai resistivitas batu gamping pada kondisi kering dibandingkan pada kondisi semi basah.

Pada model fisik dimensi kecil telah dilakukan pengukuran sebanyak 3 jenis konfigurasi pengukuran resistivitas yaitu :

- Pengukuran dengan elektroda di permukaan

- Pengukuran dengan elektroda gabuangan antara permukaan dan elektroda didalam model bawah terowongan
- Pengukuran antar elektroda samping terowongan (crosshole electrode).

Dari keempat konfigurasi pengukuran nilai resistivitas yang telah dilakukan seperti yang dijelaskan di atas, ditunjukan masing-masing kelebihan dan kekurangan masing-masing jenis konfigurasi. Dari hasil pengukuran nilai resistivitas ini didapat beberapa kesimpulan antara lain :

- Pengukuran dengan elektroda permukaan, tingkat penetarsi pengukuran hanya mencapai bagian atas, berdasarkan teori yang ada sebesar sepertiga dari panjang bentangan, sehingga pada jenis konfigurasi ini anomali yang seharusnya muncul diakibatkan adanya terowongan tidak dapat terlihat dengan baik, akan tetapi mampu memberikan informasi kondisi lapisan batuan penutup terowongan secara lateral dengan baik.

- Konfigurasi pengukuran dengan memanfaatkan gabungan elektroda permukaan dan didalam batuan di bawah terowongan, memberikan informasi nilai resistivitas yang lebih baik kondisi bawah permukaan, akan tetapi pada realisasi nyata di lapangan berdasarkan analisa akan memiliki banyak kendala, sehingga model konfigurasi ini tidak direkomendasikan.

- Pengukuran dengan konfigurasi crosshole elektroda memberikan informasi yang lebih baik secara vertikal, akan tetapi distribusi lateral sangat bergantung pada jarak antar eletroda vertikal, sehingga memiliki resolusi yang tidak baik jika jaraknya relatif jauh.

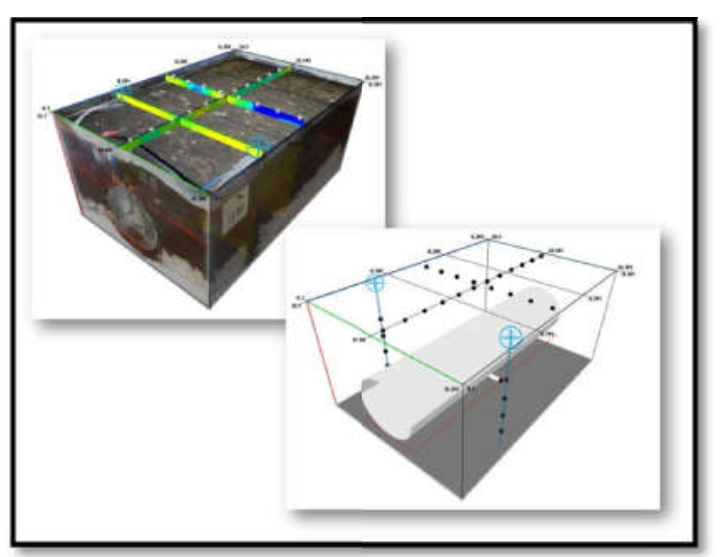

Gambar 5. Model Pengukuran pada Model Fisik Dimensi Kecil (Model b 30×20×15 cm). 
Pada Gambar 5 ditunjukan model pengukuran dan konfigurasi elektroda yang digunakan dalam pengukuran resistivitas model fisik dimensi kecil. Pada Gambar 6 ditunjukan penampang resistivitas hasil pengukuran model fisik dimensi kecil.

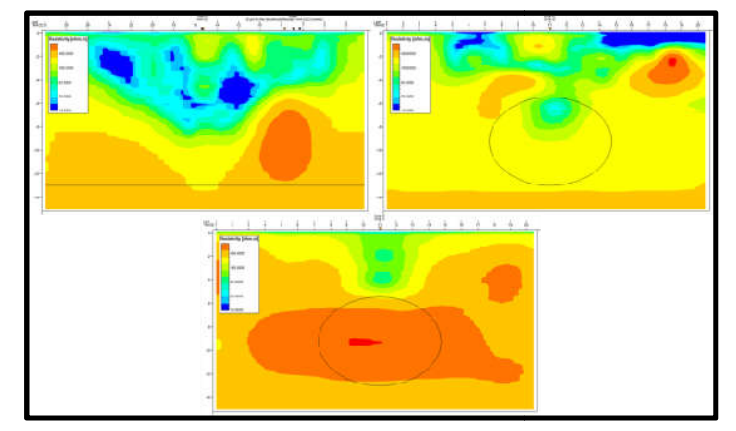

Gambar 6. Resistivitas yang Dihasilkan dari Pengukuran pada Model Fisik Dimensi Kecil (Model b $30 \times 20 \times 15 \mathrm{~cm}$ ).

Pada Gambar 6 bagian atas kiri merupakan pengukuran dengan konfigurasi elektroda permukaan memanjang sejajar dengan posisi terowongan. Pada hasil tersebut keberadaan terowongan tidak dapat terinformasikan dengan baik akan tetapi kondisi batuan penutupnya dapat terlihat dengan jelas keberadaan anomali resistivitas rendah yang ditandai dengan warna biru. Nilai resistivitas rendah ini berhubungan dengan tingkat kejenuhan air pada batuan.

Pada Gambar 6 bagian kiri atas yang merupakan pengukuran resistivitas dengan konfigurasi gabungan elektroda permukaan dan bawah permukaan arah memotong arah terowongan ditunjukan adanya anomali nilai resistivitas rendah. Pada gambar ini juga ditunjukan adanya pola jalur air yang terkonsentrasi pada posisi di tengah lintasan pengukuran.

Dari hasil dan analisa sementara yang telah dilakukan didapatkan informasi yang penting tentang bagaimana efektifitas pengukuran resistivitas batuan penutup terowongan sebagai bagian dari upaya monitoring. Metoda atau pemanfaatan konfigurasi pengukuran elektroda permukaan dan crosshole electrode merupakan konfigurasi relatif paling baik sehingga disarankan untuk pengukuran resistivitas pada model fisik dimensi besar bisa dilakukan dengan konfigurasi ini.
Final model fisik dimensi besar telah selesai dibuat seperti terlihat pada Gambar 7, dan telah dilakukan pengukuran resistivitas pada model ini dengan hanya konfigurasi elektroda permukaan.

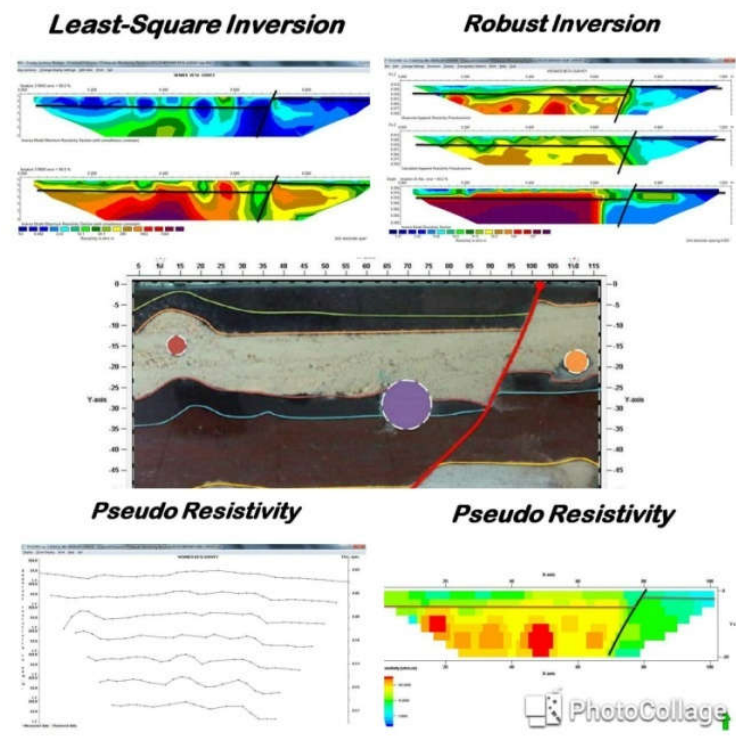

Gambar 7. Model Pengukuran pada Model Fisik Dimensi Kecil (Model b 30×20×15 cm).

Dari hasil pengolahan data geolistrik dengan konfigurasi pengukuran elektroda permukaan, dapat dilihat pada Gambar 7. Dari hasi inversi baik robust maupun least-square, ditunjukan bidang batas patahan yang sangat tegas, seperti pada model fisik yang dibuat. Akan tetapi, sesuai dengan hasil pengolahan data pada model kecil, konfigurasi pengukuran dengan elektroda permukaan hanya memberikan informasi kurang dari seperenam total bentangan, yaitu sekitar $10 \mathrm{~cm}$. Sehingga pada hasil inversi hanya tampak batas patahan dan perlapisan bagian paling atas.

\section{PENUTUP}

\section{Simpulan}

Dari hasil penelitian yang telah dilakukan didapatkan beberapa kesimpulan, antara lain :

1. Pengukuran dengan elektroda permukaan, tingkat penetrasi pengukuran hanya mencapai bagian atas, berdasarkan teori yang ada kurang lebih sepertiga dari panjang bentangan, sehingga pada jenis konfigurasi ini anomali yang 
seharusnya muncul diakibatkan adanya terowongan tidak dapat terlihat dengan baik, akan tetapi mampu memberikan informasi kondisi lapisan batuan penutup terowongan secara lateral dengan baik.

2. Konfigurasi pengukuran dengan memanfaatkan gabungan elektroda permukaan dan di dalam batuan di bawah terowongan, memberikan informasi nilai resistivitas yang lebih baik kondisi bawah permukaan, akan tetapi pada realisasi nyata di lapangan berdasarkan analisa akan memiliki banyak kendala, sehingga model konfigurasi ini tidak direkomendasikan.

3. Pengukuran dengan konfigurasi crosshole elektroda memberikan informasi yang lebih baik secara vertikal, akan tetapi distribusi lateral sangat bergantung pada jarak antar eletroda vertikal, sehingga memiliki resolusi yang tidak baik jika jaraknya relatif jauh.

4. Gabungan konfigurasi elektroda permukaan dan elektroda crosshole merupakan konfigurasi pengukuran paling baik memberikan informasi kondisi batuan penutup terowongan.

5. Keberadaan atau kejenuhan air pada batuan mampu teridentifikasi dengan baik pada pengukuran resistivitas batuan sehingga metoda pengukuran resistivitas dapat digunakan sebagai bagian dari upaya monitoring kondisi batuan di sekitar bangunan terowongan.

\section{Saran}

Dalam rangka memanfaatkan metoda geolistrik pada sistem monitoring alangkah lebih baik jika menggunakan lebih dari satu jenis konfigurasi elektroda pengukuran, misalnya menggabungkan antara konfigurasi pengukuran elektroda di permukaan dan elektroda pada lubang sumur atau bor. Dengan gabungan konfigurasi ini telah ditunjukan pada penelitian ini baik secara vertikal maupun lateral tingkat resolusinya dan kedalaman penetrasi lebih baik dibandingkan dengan hanya memanfaatkan satu jenis konfigurasi pengukuran

\section{DAFTAR PUSTAKA}

Federal Highway Administration (FHWA), 2010. Tunnel Operations, Maintenance, Inspection And Evaluation (TOMIE) Manual. United States Transportation Department.

Lashkaripour, G.R., 2003. An Investigation of Groundwater Condition by Geoelectrical Resistivity Method : A Case Study in Korin Aquifer, Southeast Iran. Journal of Spatial Hydrology Vol.3, No.1 Fall

Loke M.H., 2000. Electrical Imaging Surveys For Environmental And Engineering Studies, A practical guide to 2-D and 3-D Surveys.

Peraturan Menteri Pekerjaan Umum Nomor : 02/0/PRT/M/2014 tentang Pedoman Pemanfaatan Ruang Di Bawah Bumi (RDB). Kementerian Pekerjaan Umum.

Pidlisecky. A, Knight, R., 2008. FW2_5D: A MATLAB 2.5-D Electrical Resistivity Modeling Code, Elsevier Journal Computers \& Geosciences. Vol. 34, Page 1645-1654.

Reynolds, J.M, 1997. An Introduction to Applied and Environmental Geophysic. England:John Wiley and Son Ltd.Baffins, Chichester, West Susex P019 IUD.

Telford. W.M.., dkk, 1990. Applied Geophysics. Second Edition, New York, Cambridge University Press.

http://litbang.pu.go.id/terowongan-sebagai-solusiberbagai-masalah.balitbang.pu.go.id http://teraszaman.blogspot.com/Terowongan Air Bawah Tanah Terpanjang Di Indonesia.htm 